\title{
Cluster Centric Business Incubation: Inculcating Engineering Students on Entrepreneurial Path
}

\author{
Sharad D Kachave', Vijaykuamr.P.Wani ${ }^{2}$ \\ ${ }^{1}$ Workshop Superintendent, SSVPS B.S.Deore College of Engineering,Dhule (M.S.), 424005 \\ ${ }^{2}$ Principal, MET Institute of Engineering, Bhujbal Knowledge City, Adgaon, Nashik-422003, \\ M.S., India \\ 'sharaddkachave@gmail.com,2vpwani@gmail.com
}

\begin{abstract}
In response to the changing economic scenario due to Liberalization, Privatization and Globalization, developing nations like India has encouraged for expansion to the engineering education. Developing countries such as India are in a state of transition. They are striving to be outward looking global economies rather than inward looking local economies, which will be possible only if small and medium-scale enterprises are encouraged. If technical institutions are to carry out their dual function of education and developing an entrepreneurial workforce for the sustainable development of MSMEs, then it is important that its students should be involved in solving real problems of practical importance to industry as a part of their professional training.
\end{abstract}

This paper discusses the strategies for developing entrepreneurial vision amongst engineers by following cluster centric business approach, the significance of industry/institute interaction, the role of engineering education and the impact of engineering education in the growth of small and medium enterprises.

\section{Sharad D Kachave}

Workshop Superintendent, SSVPS B.S.Deore College of Engineering,Dhule (M.S.), 424005

sharaddkachave@gmail.com
Today almost all students prefer wageemployment as a career option. This has been aggravated by our education system, which promotes wage-employment for students rather than selfemployment. An engineer, through technical entrepreneurship, can bring a technical revolution that can meet the challenges of the emerging scenario of globalization and liberalization with key elements of competition rather than protection.

The paper discuss over the case study, wherein typical problem of textile industry's knitting unit in local area was taken up by the student under project. They have undergone the in plant study and addressed the problem by designing, developing and implementing a system. The impact of the efforts is assessed from the point of view of entrepreneurship development of the student as well as from technology business incubation.

Keywords: Engineering education; Cluster centric approach; entrepreneurship; technology business incubation.

\section{Background:}

This paper discusses the strategies for developing entrepreneurial vision amongst engineers by following cluster centric business approach, the significance of industry/institute interaction, the role of engineering education and the impact of engineering education in the growth of small and medium enterprises. Today almost all students prefer wage-employment as a career option. This has been aggravated by our education system, which promotes 
wage-employment for students rather than selfemployment. An engineer, through technical entrepreneurship, can bring a technical revolution that can meet the challenges of the emerging scenario of globalization and liberalization with key elements of competition rather than protection.

The paper discuss over the case study, wherein typical problem of textile industry's knitting unit in local area was taken up by the student under project. They have undergone the in plant study and addressed the problem by designing, developing and implementing a system. The impact of the efforts is assessed from the point of view of entrepreneurship development of the student as well as from technology business incubation.

The small-scale sector has emerged as the most dynamic and vibrant sector in recent times. Small and medium enterprises worldwide and small-scale sector in India is the backbone of economy. The developing countries like India realized the importance of this sector and gave encouragement for its growth through various incentives, subsidies, and reservation of items exclusively for this sector. In spite of all these initiatives, It is a fact that SSI Sector has not been developed to its fullest potential. The changing economic environment due to liberalization, privatization, and globalization has posed certain challenges and has provided opportunities to the Small-Scale Industrial (SSI) Sector. The challenges are in the form of increased competition, shorter life cycle of products as well as technology, reduced protection due to lower tariffs, and market determined rate of interest. On the other hand, the opportunities have come in the form of access to better technology, availability of a variety of raw materials and components, impetus to quality, efficiency, and opportunities to restructure and diversify. To face these challenges and grab the opportunities, an entrepreneur has to adopt innovative product process, productivity improvement techniques, and effective technology management for sustainability of the unit. Here the innovative approach will be the remedy for an entrepreneur for sustainability.

\section{Developing Entrepreneurship for Sustainable Growth of MSME Sector}

It is a fact that with proper education and training provided to the person with entrepreneurial zeal, sustainable entrepreneurship could be developed. Bhat Khursheed [1] supports this when he carried out experiment in the two towns of Andhra Pradesh in collaboration with Small Industries Extension Training Institute (SIET) Hyderabad. It is a universal fact that education and training of potential entrepreneurs has a significant bearing on the successful pursuits of entrepreneurship, yet the question arises what training inputs are needed for the potential entrepreneurs [2]. The entrepreneurs of SME sector have to discharge the twin functions of 'entrepreneur' and a multifarious 'manager'. So the need is to make them:

口 Highly knowledgeable and dynamic in their field of study and also outline about the other related fields;

u Fully aware of the different schemes / incentives being offered to MSME sector and procedures thereon; Life long learning process should be inculcated in the minds of the students.

u Understand the different laws, regulations and procedures to be followed in the establishment of a unit;

口 By impressing the students about the importance of keeping in mind the vision and

mission of the institution where he / she is associated with at that time.

( Understand how important it is to submit to financial discipline;

口 By including the case studies or field study as part of the subjects and also beyond syllabus where common things are to be educated.

口 Value education has to be continued to the required / needy during the course of study.

口 Understand how to seize an opportunity and thereof in the conduct of market survey studies and preparation of project cum feasibility report;

口 Marshal and utilize the knowledge as well as resources in an effective way for the success of the industrial venture.

Secondly, in the context of globalization and liberalization, the industries are to respond to the emerging calls of quality assurance as well as costeffective strategies of production and services. The management of new enterprises and establishments has, therefore, to respond to the management of technological growth and innovation. This challenge of growing competition has necessitated high degree of application capability and innovation spirit among the entrepreneurs. Innovation is to be initiated by entrepreneur by seizing an opportunity in the changing situation by discovering how to: 
u Make sure that all innovations create the customer delight and meet high quality standards;

口 Bring innovativeness into every important and crucial processes from planning to communication feedback system

․ Find paradigm to keep on the cutting edge of change;

u Study the past, analyse the present and forecast the needs of the customer as well as the technology in the unit for its sustainability;

口 Establish a shared vision that involves all members of unit in fostering and achieving important innovation synthesis of opportunities of market place with both the capabilities and need of stockholders.

\section{Necessity of Engineer as Entrepreneur:}

To face the challenges posed to the small-scale sector due to changing technical and economic environment, the entrepreneur has to adopt innovative products / processes, productivity improvement techniques and effective technology management [3]. Kelmer and Wanghman [4] considered technology process as important, but the ability to utilize and capitalize on the advantage of technology through invention and innovation subsequently achieving through synergy is considered more important in running and survival of unit.

Sangavi [5] rightly described the role of technical entrepreneurship, which is pivotal in the process of liberalization. It can make a contribution to industrial development through innovations, new product / process development /improvement in productivity etc. Technicians and technocrats can play the role of innovators with comparatively ease because they have characteristics such as propensity to adopt to new knowledge more rapidly. Technologists and technicians who learn sufficient science and engineering acquire capabilities to know why and how of various theories and can design products and services based on their knowledge and skill competencies [6].

In the fast changing technological environment, the role of technical entrepreneurship has assumed a central place. Moreover as per Baburao G [7], favorable factors for technical person who can be an effective entrepreneur, after proper education and training, can be as follows:

i. Ability to grasp opportunities which offers economic advantage;

ii. Ability to analyze and diagnose the problems of production and service of an enterprise and device remedial measures at the right time;

iii. Ability to workout economics of production and service outputs and evolve competitive and cost effective strategies;

iv. Ability to give fillip to ancillarization, thus help in better linkage between large and small enterprises;

v. Safety has to be taught as part of value education along with technical and analytical subjects.

vi. Ability to forecast the changes in technology and adopt to the changing environment more easily;

vii. Commitment to work / perform duties - as part of value education.

viii. Ability to effectively transfer technology from laboratories to industries.

ix. Engineers as entrepreneurs can meet the challenges of emerging scenario of liberalization, privatization, and globalization with key elements of competition rather than protection.

\section{Challenges before Engineering Education}

As per Natarajan [8] engineering practice today has changed dramatically \& irreversibly due to:

i. Growing global competition and the subsequent restructuring of industry;

ii. Shift from defense work to private enterprise as major source of engineering employment;

iii. Explosion of information;

iv. Development of information and technology.

Webster John [9] has emphasized engineering education should equip graduates to demonstrate the attributes which are similar to entrepreneurial characteristics. In technical education, emphasis has to be given on nurturing entrepreneurship to enable the engineering students to be the champions of the product and process, market system practices and help in professionalizing the small-scale sector.

Prakasam V Gnana [10] observed that the present system of engineering education has very little practical application, as graduates are ignorant of field practices. As a result there is a lack of vision, creativity, innovative ideas, and diagnostic skill among the students. Therefore, the technical graduate coming out of the technical institution, in spite of lack 
of wage employment, prefers job hunting than going for self-employment as a career option.

\section{Role of Technical Institutions in Entrepreneurship Development}

The success in improving the quality of engineering education depends upon a planned and disciplined approach. Vaidya and Jain [11] views the global perspective of technical education, thus reveals an ever increasing to the system itself to make it respond to the expectations of the industry as well as society. Raj Gopalan [12] sees that, the economic development of any country depends on its industrial growth and productivity, which is directly related to the quality of engineers coming out of the technical institution. The quality of engineers in turn has a direct bearing upon the quality of technical education imparted to them. As per Mittal [13] the excellence in technical education can be achieved by joint efforts, specially the enthusiastic support and commitment of faculty particularly as 'Agents of change'. Faculty is the asset of any institution. If it is well developed, dedicated and devoted in its pursuit of excellence in education, students automatically gets developed and achieves high standards.

As per Bhansali [14], engineering education in India has never been given due importance by educationists as well as planners. In India, no effort has been made to build technical human force to meet the future challenges. Therefore, Bhansali has stressed upon the necessity of industry-institute interaction as an integrated part of engineering education, which will be helpful in transforming an engineer from a jobseeker to a job creator. On engineering education, Stuart-G-Walsh [15] warned that if we do not redefine and refine our educational programmes, someone else would do it for us.

In engineering education efforts are to be made to develop entrepreneurship in the students. The necessity of developing a creative design, methodology, or several of them to suit individual idiosyncrasy is unquestionable. Its usefulness for developing creativity in students has been verified by many teachers. But the fact remains that the methodology of creative thinking alone cannot turn an engineer into an entrepreneur, unless he has the required amount of insight. To develop necessary insight, Karune [16] has emphasized on only one method, and that is presenting the principles from known to unknown, from old concepts to new ones, from simple problems to complex problems involving several laws. This will give the students, the right insight and develop his confidence in meeting new situations with initiative and originality.

\section{Entrepreneurship Development: ANecessity}

Entrepreneurship is essential for the continued dynamism of the modern market economy, and a greater entry rate of new businesses can foster competition and economic growth [17, 18]. Technological innovation and entrepreneurship are the new forces for economic growth worldwide [19]. Entrepreneurial, as well knowledge based, small and medium enterprises are the backbone of the private sector as they offers a wide range of goals and services both to national and international markets. Most countries formulated strategies for promoting innovation and assisting small entrepreneurs / enterprises in acquiring technological resources.

A higher level of entrepreneurship significantly relates to greater economic development, formal sector participation, and better governance. Countries with lower barriers to entry and less corruption generally see higher percentages of firm registrations and entry [20]. Developing countries have to drastically restructure their strategic plans, develop the skills needed, and build new structures, in order to survive and thrive in the globalizing environment. Government has to reinforce their policies and develop infrastructure, while the learning system helps build the new age skills and support entrepreneurship development [21]. Entrepreneurship is increasingly recognized as being vital to the regeneration and development of economics with the advent of the so-called 'Enterprise Culture'. There has been wide spread acceptance that entrepreneurship is the engine that drives the economy of most nations. Anderson perceives entrepreneurship to bring benefits at the macro level of economic development and at the micro level for personal achievement and satisfaction [22]. As per Evans and Hanson for teaching and development in effective way, the entrepreneurship career path has been decomposed into five stages [23].

i.Foundation: Creation and reinforcement of entrepreneurial values bound for individual and society as whole;

ii. Awakening: Confrontation of an individual with entrepreneurship as a viable career option; 
iii. Specialization: Acquiring skills for business creation helping individual to identify as an entrepreneur.

iv .Creation: The individual moves from knowledge and learning to action.

v. Maturing: Individual builds on his experience, advances his career through Knowledge based development and networking.

vi. To have a clear understanding of the process of entrepreneurship development Sharma [24] has been put into three features as follows:

vii. Initiation: Stimulation for entrepreneurship, identification, and selection of persons.

viii. Development:: Motivation economic insight, management skills, creating confidence etc.

ix. Support: Extension of support for the establishment and running of an enterprise.

While emphasizing alternative approaches in entrepreneurship education Laukkanen [25] mentioned that entrepreneurship as instrumental in economic growth, balanced regional development, and for creating jobs. To fulfill what is called their 'third obligation' academic institutions and universities are expected to contribute by research, teaching, and transfer of technology. Entrepreneurial education is one of the responses to the realities.

As per the study conducted by London Business School and Babson College on features making a country more or less entrepreneurial, the country is regarded as more advanced in the entrepreneurial sense, if it has got more favorable entrepreneurial culture than other countries [26]. While making an entrepreneurial global manager, the first broad opportunity lies in the entrepreneurial managers ability to rapidly introduce new products, exploit new source of raw materials (most often by new technologies) and recognize the input and output inter and intra-firm linkages [27].

Much of business education prepares the students for life in the administrative domain. But the education-preparing students to start and manage vibrant, growing new venture cannot afford to emphasis administrative efficiency, maintenance tasks, resources ownership, and institutional formalization. Rather it needs to emphasis skills necessary for life in entrepreneurial domain [28].

The entrepreneurial development program should be theoretical at first instant then practical oriented. Thus the complete curriculum of the entrepreneurship development programme should be adopted as follows:

i. Pre-operational drill;

ii. Operational drill;

iii. Post-operational drill;

iv. Functional \& structural parameters,

v. Competence building for decision-making.

The first three stages will be for technical \& remaining two for managerial competence building. The detail coverage of the proposed entrepreneurial development twenty point program would be as detailed below [29]:

Table 1. Twenty point Propsed Programme

\begin{tabular}{|c|c|}
\hline Step & \begin{tabular}{|c|} 
Process \\
\end{tabular} \\
\hline $\begin{array}{l}\text { Pre- } \\
\text { operational } \\
\text { drill }\end{array}$ & $\begin{array}{l}\text { 1. Making students to know him / her self. } \\
\text { 2.Identification of Entrepreneur } \\
\text { 3.Individuals decision to ch } \\
\text { employment as career. }\end{array}$ \\
\hline $\begin{array}{l}\text { Operational } \\
\text { drill }\end{array}$ & $\begin{array}{l}\text { 4.Opportunity recognition. } \\
\text { 5..Product identification. } \\
\text { 6.Self-confidence building. } \\
\text { 7.Techno-commercial aspects of unit. }\end{array}$ \\
\hline $\begin{array}{l}\text { Post- } \\
\text { operational } \\
\text { drill }\end{array}$ & $\begin{array}{l}\text { 8.Vetting of techno -economical viability of } \\
\text { proposed unit. } \\
\text { 9.Vetting of project report from the financial } \\
\text { institutions. } \\
\text { 10.. Technical sustainability of the unit. }\end{array}$ \\
\hline $\begin{array}{l}\text { Functional } \\
\text { and } \\
\text { structural } \\
\text { parameters }\end{array}$ & $\begin{array}{l}\text { 11.Land/ Shed allotment for the unit. } \\
\text { 12.Resource generation for the unit. } \\
\text { 13.Technical know-how for the unit. } \\
\text { 14.Rules, Regulations of the land. }\end{array}$ \\
\hline $\begin{array}{l}\text { Competence } \\
\text { building for } \\
\text { decision } \\
\text { making }\end{array}$ & $\begin{array}{l}\text { Development of: } \\
\text { 15.Leadership qualities, } \\
\text { 16.Decision making ability, } \\
\text { 17.Labor management skill, } \\
\text { 18. Finance management skill, } \\
\text { 19.Sales,marketing and purchase management } \\
\text { skill, } \\
\text { 20.Shop-floor management skill. }\end{array}$ \\
\hline
\end{tabular}

This process will make students aware about the steps in entrepreneurship as follows:

口 To be well versed with product line, just knowing manufacturing/service process/ method is not sufficient. Process/method know-how and know-how to operate the ---machine/ equipment is must.

口 Sufficient shop floor experience to guide operational staff at different level.

u Familiar with raw material requirements, their specifications, availability, source of supply price etc. 
Q Quality requirements of product, measures for improving quality.

口 Marketing \& distribution networks and practices, transport intricacies, cost of packaging \& presentation.

( Well versed with taxation and other regulatory rules.

( Maintain accounts, stores inventors in efficient way.

Q Willingness to put with bureaucratic regulations, environmental turbulence, \& ability to move with wind.

( Ability to identify the opportunity and avail opportunity benefits.

૫ Quality expertise, shrewdness, resourcefulness, perseverance.

口 Follow five ' $\mathrm{P}$ ' principles i.e. Planning, Preparation, Persuasion, Patience, and Perfection for running industrial venture successfully.

口 Should be physically and mentally tough to withstand neck-to-neck competition from the similar units and business rivals.

\section{Case Study}

A typical process in the knitting industry is a as shown below:

The quality of the end product depends on the quality of knitted and dyed (finished) fabric. The QC is done at the following two stages 1 . After knitting process on grey fabric 2. After Dyeing process on finished fabric.

The fabric rolls are kept in front of the inspection machine and are visually inspected by the operator over the inspection machine. This is called as offline inspection method. The knitted fabric is inspected for major or minor faults like barre mark, fly, holes oil lines, and needle lines slubs etc. which are produced during knitting process.

If inspection is not done properly these faults will remain during dyeing process and affects the quality of the dyed fabric or finished fabric.

The inspection machine is shown in below pictures:
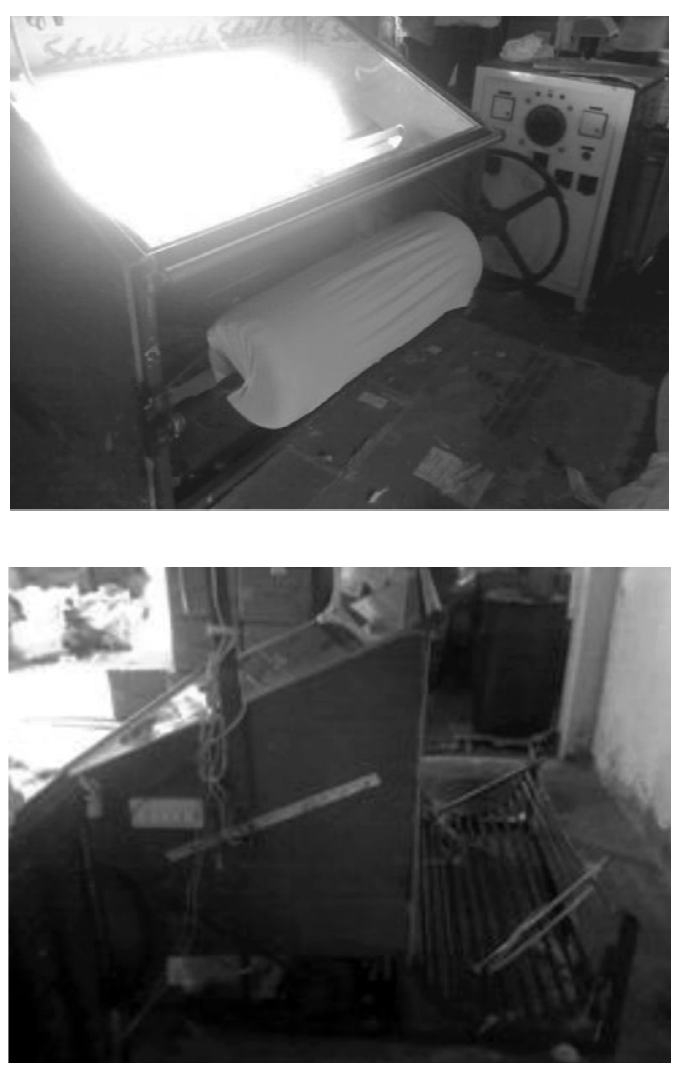

Fig. 1 Without fabric Roll

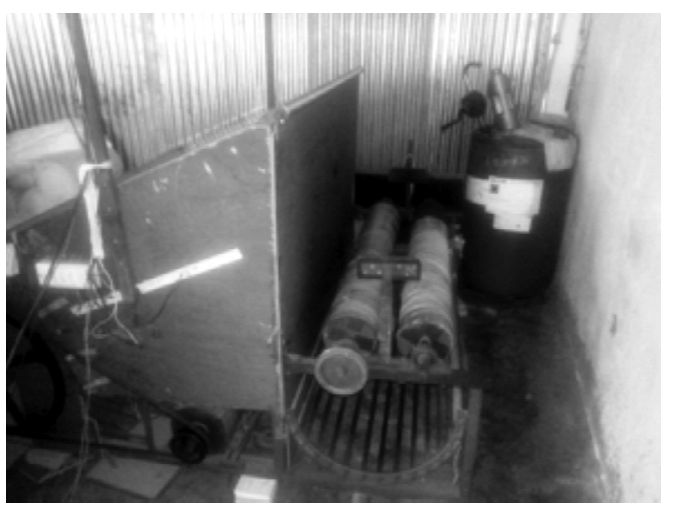

Fig.2 Without fabric Roll

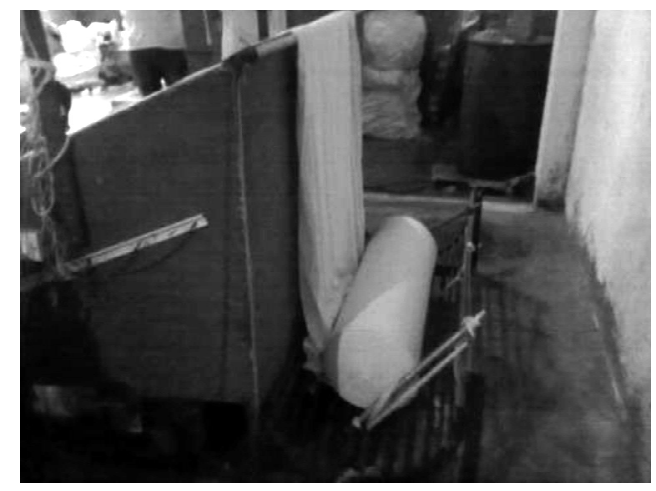

Fig.3 With Fabric Roll Existing Machine (manual) 


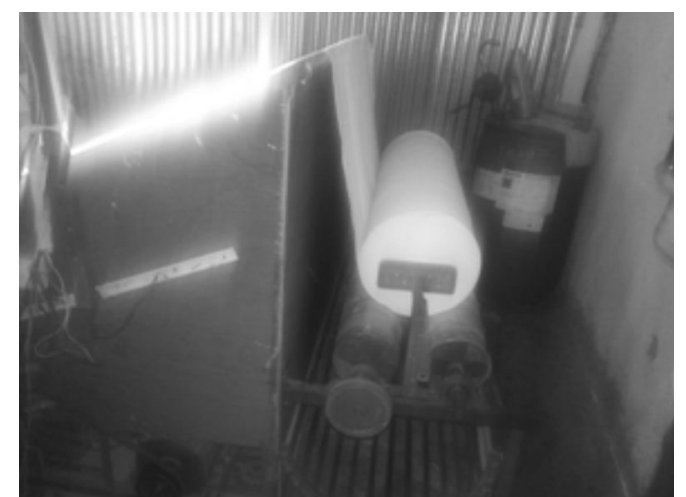

Fig.4 With Fabric Roll Modified Machine (automation)

Problem identification:

In the knitting industry many times, it is needed to develop or provide customized solutions for day to day problems. As the industry has installation of many legacy machineries, it is needed to design machineries and mechanisms with a given specific constraints. Every time it is not possible to replace whole system installation completely.

In the case study undertaken here, we have designed and implemented a sub system as a add-on to the existing fabric inspection machine.

As shown in figure 1 the typical machine which is human operated. Here an operator pulls the fabric roll onto the glass table to inspect the fabric. Due to manual pulling many times he may pull unevenly resulting in rewinding and repulling of the roll. This also results in fatigue and time wastage. This process is highly error prone.

Here we should develop an attachment as a sub system to solve most of the potential problems. The supervisors decided to develop the solution as a task for inculcating entrepreneurial skills in under graduate students.

Students studied and analysed the problem. With the help of supervisors they designed the attachment as shown in figure 2 .

The attachments subsystem houses operator side roll which is automatic: which pulls the fabric evenly and with same speed? This makes operator's operation mostly hands free. This also improves operator productivity and makes most of the operation error free. i. Cost

\section{ii. Efficiency}

iii. What students learnt: Communication, selection of optimal solution from many available alternatives within given constraints, material selection, cost saving, real world project

\section{Conclusion}

Technical Institutes can play an important role in the development of entrepreneurial workforce for the sustainable development of the MSMEs. They can implement Technology business incubation within their curriculum. It will also improve instituteindustry interaction and enable students to work on real life industry projects. In turn this movement will speed up the share of students opting for self employment.

\section{References}

[1] Bhat Khursheed, "Small Entrepreneurial Education: Approach and Methodology", Abhigyan, Volume XVII, No. 4, 1999, pp-35-44

[2] Wani V. P., Garg T. K., Sharma S. K., "Role of Engineering Education in Developing Entrepreneurial Capabilities among Engineers for Sustainability of SME's in Inda", ASEE/SEFI/TUB, International Colloquium on Engineering Education, Berlin (Germany), October 2002

[3]http://www.education.nic.in/htmlweb/techedu.hm Growth of Engineering and Technology in India

[4] Kelmer and Wanghman D. W., "Determining the Relevant factors in the Success Strategies of Small Enterprises", Journal of Entrepreneurship, July-September 1995, pp-215-236

[5] Sanghvi A. N., "Promotion of technical Entrepreneurship through Technical education", The Indian Journal of Technical Education, 19, 2, April-June 1996, pp-42-44

[6] Baburao G., "Entrepreneurial education in Technical School", Hindu, 1995

[7] Baburao G., "Promotion of Technical Entrepreneurship: Role of Humanities and Social Sciences", Journal of Engineering Education, Jan.1999, pp-7-11

[8] Natarajan R., "The Role of Accreditation in Prompting Quality Assurance of Technical Education", International Journal of 
Engineering Education, Vol.16, No.2, 2000, pp84-96

[9] Webster John, "Engineering education in Australia", International Journal of Engineering Education, Volume 16, No.2, 2000, pp-146-153 (B)

[10] Prakasam V. Gnana, "Industry Institute Linkages", National Seminar Entrepreneurship and Technology Development, Role of industries at Delhi College of engineering, Delhi March 1994

[11] Vaidya A. M., and Jain B. C., "Quality Improvement in Technical Institutions through TQM", National Conference on TQM in Technical Education at MACT Bhopal, December 1996, pp-55-58

[12] Raj Gopalan T., "Technical Education in India", The Hindu, Madras, 12/10/95

[13] Mittal N. K., "Twenty Point programme for Implementing T. Q. M. in Technical Education", National Conference on TQM in Technical Education, MACT Bhopal December 1996, pp$15-25$

[14] Bhansali V. K., "Strategies Conductive to Industry Institute Linkages", Conference on Entrepreneurship and Technology Development, Delhi College of Engineering, Delhi, March 1994

[15] Walesh Stuart G., "Engineering a New Education", Journal of Management in Engineering, March-April 2000, pp-35-41

[16] Karune S., "Entrepreneurship Characteristics and Fostering Entrepreneurship among Engineers", Indian Journal of Technical Education, Volume 10, No.2, July1987, pp-30-33

[17] Klapper, L., L. Laeven, and R. Rajan, 2006, Entry regulation as a barrier to entrepreneurship. Journal of Financial Economics, 82: 3, 591-629.

[18] Djankov, S., R. La Porta, F. Lopez-de-Silanes, and A. Shleifer, 2002. The regulation of entry. Quarterly Journal of Economics, 117, 1-35.

[19] Lalkaka Rustam, "Venture Creation and Growth through Business Incubators and Technology Parks", Proc. of Intl Sem. on Best Practices for Collaboration.http://www.waitro.dti.dk/Publica tions/Seminars/Best_Pra/Lalkaka.html

[20] Leora Klapper, Raphael Amit, Mauro F. Guillén, February2008,http://siteresources.worldbank.or g / I N T F R/R e s o u r c e s / 475459 22364030476/FirmFormation_NBER.pdf

[21] Lalkaka Rustam, "New Strategies, Skills \& Structures for Technological Innovation", XVI IASP World Conf.on Technology Parks, Turkey, Sept. 1999.

[22] Anderson A. R., and Sarah L.J., "Teaching the Entrepreneurial Art", a.r.Anderson@abdn.ac.uk

[23] Evans D.S, and Hanson. M., "Environmental Contingencies in Teaching Entrepreneurship: The Case of France", devans@escem.fr

[24] Sharma, "Entrepreneur and Innovation", SEDME 27-1, March 2000, pp-32-39

[25] Laukkanen.M., "Exploring Alternative Approaches in High Level Entrepreneurship Education: Creating Micro Mechanisms for Endogenous Regional Growth", Entrepreneurship and Regional Development, 12(2000), pp-25-47

[26] Psenicoy Viljem, "Lessons from the Most Dynamic Enterprises in Slovenia and EU Member States", 2nd International Conference on Dynamic Entrepreneurship, GEA College of Entrepreneurship, Portoroz, Slovenia, 16th February, 2001

[27] Jain A.K., "The Making of an Entrepreneurial Global Manager", Vikalpa, Vol.21, No.1, January- March 1996, pp-15-21

[28] Timmons Jeffry A., "New Venture Creation: Entrepreneurs for the 21st Century", pp-216

[29] Wani V. P., Garg T. K., Sharma S. K., 2002. Developing the Entrepreneurship through Technical Education in India for Sustainable Industrial Development, Third Global Congress on Engineering Education, Scotland 